\title{
Ring opening and ring expansion of 8-cyano-tetrazolo[1,5-a]pyridine with secondary amines. Reactions of azides, tetrazoles and nitrenes with nucleophiles, Part $2^{1}$
}

\author{
Chris Addicott, Paul V. Bernhardt, and Curt Wentrup* \\ School of Chemistry and Molecular Biosciences, The University of Queensland, Brisbane, Qld \\ 4072, Australia \\ E-mail: wentrup@uq.edu.au
}

Dedicated to Professor Henk van der Plas on the occasion of his $80^{\text {th }}$ birthday

\begin{abstract}
8-Cyanotetrazolo[1,5-a]pyridine 6T undergoes photochemical ring expansion to afford 1,3diazepine 7 with diisopropylamine, but with stronger nucleophiles such as dimethylamine a rapid, quantitative ring opening reaction affords dienyltetrazoles $\mathbf{8}$ and $\mathbf{9}$ in the dark (an Addition of Nucleophile - Ring Opening reaction).
\end{abstract}

Keywords: Pyridine, tetrazole, nucleophilic ring opening

\section{Introduction}

Heterocyclic compounds undergo numerous and sometimes unexpected transformations. ${ }^{2}$ The formation of substituted 2-pyridylformamidines $\mathrm{PyNCHNR}_{2}$ and 2-pyridylhydrazines $\mathrm{PyNHNR}_{2}$ in dark reactions of valence tautomeric tetrazolo[1,5- $a$ ]pyridines/2-azidopyridines and amines was described in Part 1. ${ }^{1}$ Tetrazolo[1,5-a]pyridines/2-azidopyridines 1T/1A are also convenient sources of $1 H$ - and $5 H$-1,3-diazepines (e.g. $1 H$-diazepines 4) and diazepinones 5 via ring expansion of photochemically (and sometimes thermally) generated 2-pyridylnitrenes 2 to 1,3diazacyclohepta-1,2,4,6-tetraenes $\mathbf{3}$ followed by trapping with nucleophiles, most commonly amines, alcohols, and water. A large number of 1,3-diazepines $\mathbf{4}$ and diazepinones $\mathbf{5}$ have been prepared in this way as illustrated in Scheme $1 .^{3-5}$ 


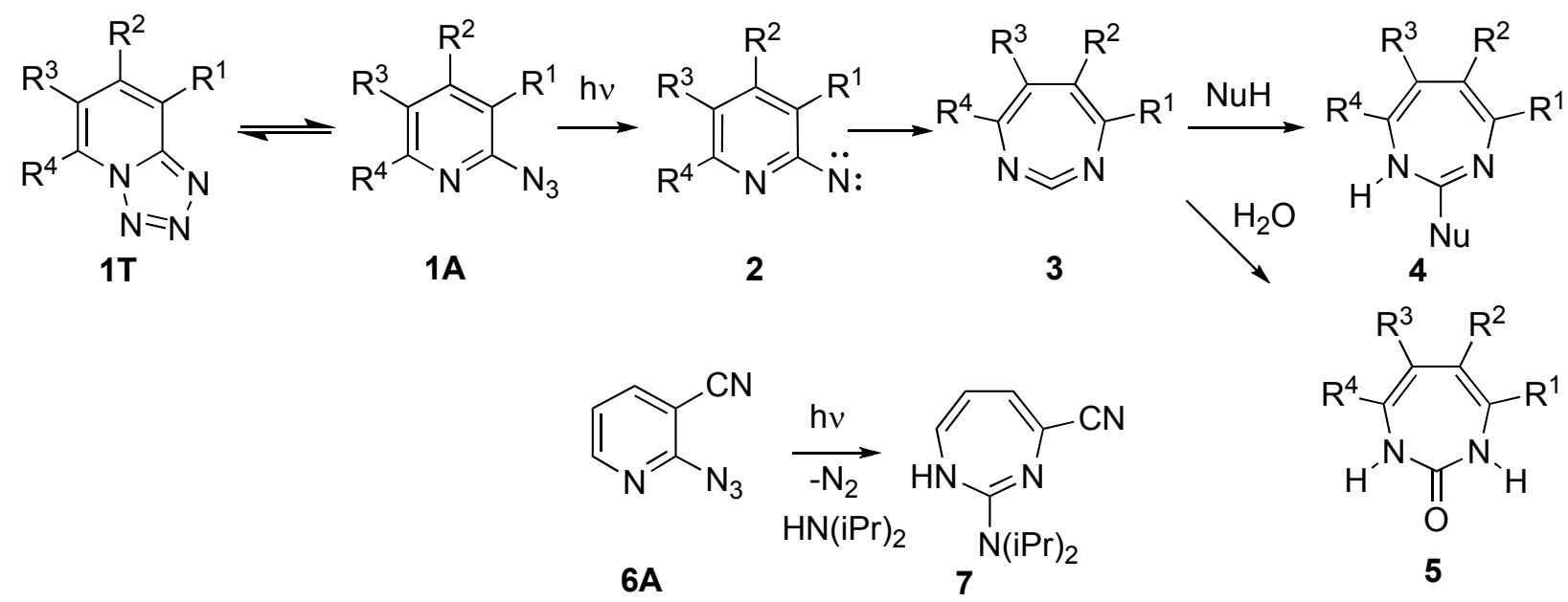

\section{Scheme 1}

Here we report that 8-cyanotetrazolo[1,5-a]pyridine/2-azido-3-cyanopyridine $\mathbf{6 T / 6 A}$ undergoes photochemical ring expansion to afford $1 \mathrm{H}$-1,3-diazepine 7 in the presence of diisopropylamine. Other diazepines and a diazepinone analogous to 5 were obtained with alcohols and water. ${ }^{5}$ However, no diazepine product was isolable from the reaction with the more nucleophilic dimethylamine. Instead, a rapid ring opening reaction took place in the dark.

\section{Results and Discussion}

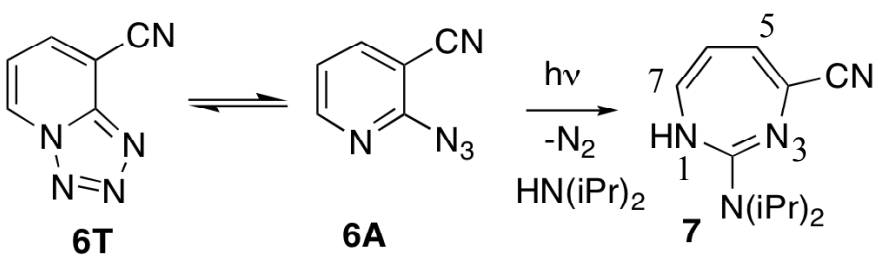

\section{Scheme 2}

8-Cyanotetrazolo[1,5-a]pyridine 6T exists as the tetrazole in the solid state. The azide valence tautomer 2-azido-3-cyanopyridine 6A was not detectable in the IR (KBr) or NMR (DMSO) spectra. Photolysis of a dilute solution of 6T in acetonitrile containing diisopropylamine afforded the 1,3-diazepine 7 as orange crystals in $47 \%$ yield (Scheme 2). The structure was ascertained by NMR spectroscopy, drawing on our previous investigations of diazepines. ${ }^{3-5}$ In the ${ }^{1} \mathrm{H}$ NMR spectrum a doublet at $5.78 \mathrm{ppm}$ is assigned to H-5, and a broader doublet at $6.20 \mathrm{ppm}$ to $\mathrm{H}-1$. Assignment of two triplets at 5.06 and 5.70 ppm to $\mathrm{H}-6$ and $\mathrm{H}-7$, respectively, was confirmed by homonuclear decoupling experiments. In the IR spectrum, the NH and CN stretching absorptions appeared at 3375 and $2221 \mathrm{~cm}^{-1}$, respectively. 
The same type of diazepine synthesis could not be achieved with dimethylamine and other strong nucleophiles (diethylamine and pyrrolidine) because 6T reacts rapidly with these amines in the dark at room temperature by nucleophilic attack on C-5 of the pyridine ring to form the ring-opened butadienyltetrazoles $\mathbf{8}, \mathbf{9}$ as shown in Scheme 3.

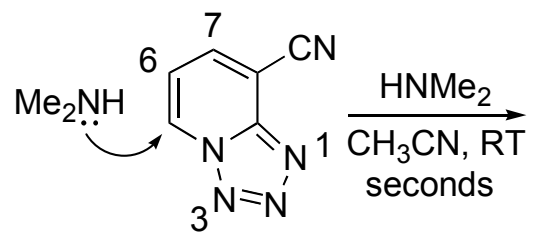

6T

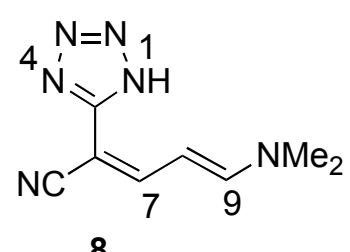

8

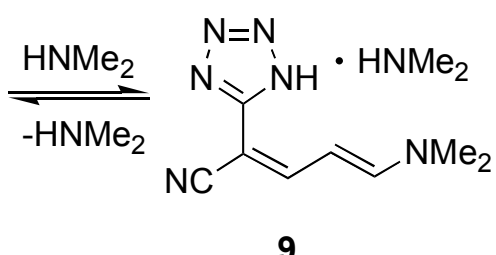

9

\section{Scheme 3}

The acetonitrile solution of 6T turned yellow immediately upon admission of dimethylamine gas. After evaporation and recrystallization, the dimethylamine adduct $\mathbf{9}$ of the dienyltetrazole $\mathbf{8}$ was obtained as yellow needles. The ${ }^{1} \mathrm{H}$ NMR spectrum of 9 showed two singlets at 2.60 and $2.95 \mathrm{ppm}$, each integrating for six protons and assigned to the methyl groups. The latter signal was quite broad, probably due to hindered rotation of a dimethylamino moiety. A triplet at 6.50 ppm and two doublets at 6.97 and 7.12 ppm were assigned to the vinylic H-8, H-7 and H-9, respectively. No other geometric isomers were observed. The infrared spectrum showed a medium nitrile stretching vibration at $2201 \mathrm{~cm}^{-1}$. The extraneous $\mathrm{H}$-bonded dimethylamine was removed from 9 by dissolution in water and addition of $\mathrm{HCl}$, thus affording the free base $\mathbf{8}$. In the ${ }^{1} \mathrm{H}$ NMR spectrum of $\mathbf{8}$ there were two broad methyl group signals at 2.97 and 3.18 ppm due to the slow rotation of the dimethylamino group. The H-8 proton signal (5.46 ppm) was at $c a .1$ ppm higher field than the corresponding signal in 9, while those for H-7 and H-9 were shifted downfield by $0.5-0.7 \mathrm{ppm}$. This can be explained by an allylic resonance whereby the $\mathrm{NMe}_{2}$ lone pair is delocalized onto $\mathrm{C} 8$, whereas $\mathrm{C} 9$ becomes an iminium ion carbon. This gives the NC9 bond some double bond character, as is clearly indicated in the X-ray structure described below. The ${ }^{13} \mathrm{C}$ NMR spectrum of 8 showed two methyl group signals at 37.2 and $44.8 \mathrm{ppm}$, the vinylic carbons C6 - C9 at 74.7, 152.2, 95.5, and 157.5 ppm, respectively, the tetrazole carbon $\mathrm{C} 5$ at 153.9, and the nitrile carbon at $117.7 \mathrm{ppm}$. The CN stretching absorption appeared at 2206 $\mathrm{cm}^{-1}$ in the infrared spectrum.

The crystal structure of compound 8 , crystallized as its hemi-methanol solvate $(\mathbf{8} \cdot 1 / 2 \mathbf{M e O H})$, was determined. The structure comprises four independent tetrazoles in the asymmetric unit in addition to a methanol molecule refined at half occupancy and disordered over four different sites. A view of molecule 'A' is shown in Figure 1. The four tetrazoles (molecules A, B, C and D) have the same $Z-E$ configuration, where the NH group in the ring is anti to the cyano group. In each molecule, the terminal $-\mathrm{NMe}_{2}$ group is conjugated with the diene backbone as evident from the C9n-N10n ( $n=\mathrm{A}, \mathrm{B}, \mathrm{C}$ and D) bonds (1.312(4) - 1.319(4) $\AA$ ) which approach those of typical $\mathrm{C}=\mathrm{N}$ double bonds. The four independent tetrazole molecules are essentially planar, and 
all atoms lie within $0.2 \AA$ of the least squares plane calculated from all non-H atoms. Each $\mathrm{NH}$ group $(\mathrm{N} 1 n)$ donates an $\mathrm{H}$-bond to $\mathrm{N} 3 n$ on an adjacent molecule.

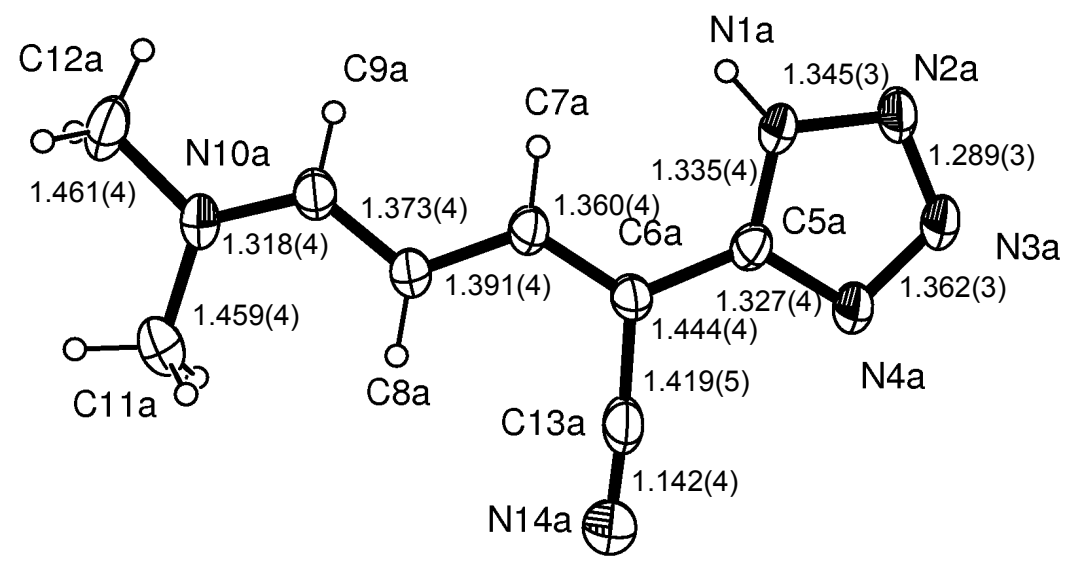

Figure 1. ORTEP view of compound $\mathbf{8}$ (molecule A, 30\% probability ellipsoids).

Both 8 and 9 eliminate dimethylamine when passed through a heated gas chromatography column. The GC trace and mass spectra demonstrated that tetrazolopyridine 6T was regenerated. This also happened when an acetonitrile solution of 9 was heated to $50^{\circ} \mathrm{C}$.

We assume that $E-Z$ isomerization in $\mathbf{8}$ can take place easily on heating. Cyclization can then take place via attack of the formally negatively charged tetrazole $\mathrm{N} 4$ on the iminium-type carbon atom C9 to regenerate the adduct $\mathbf{1 0}$ (a 'covalent amination' product), which reverts to 6T by elimination of dimethylamine, as illustrated in Scheme 4 below.

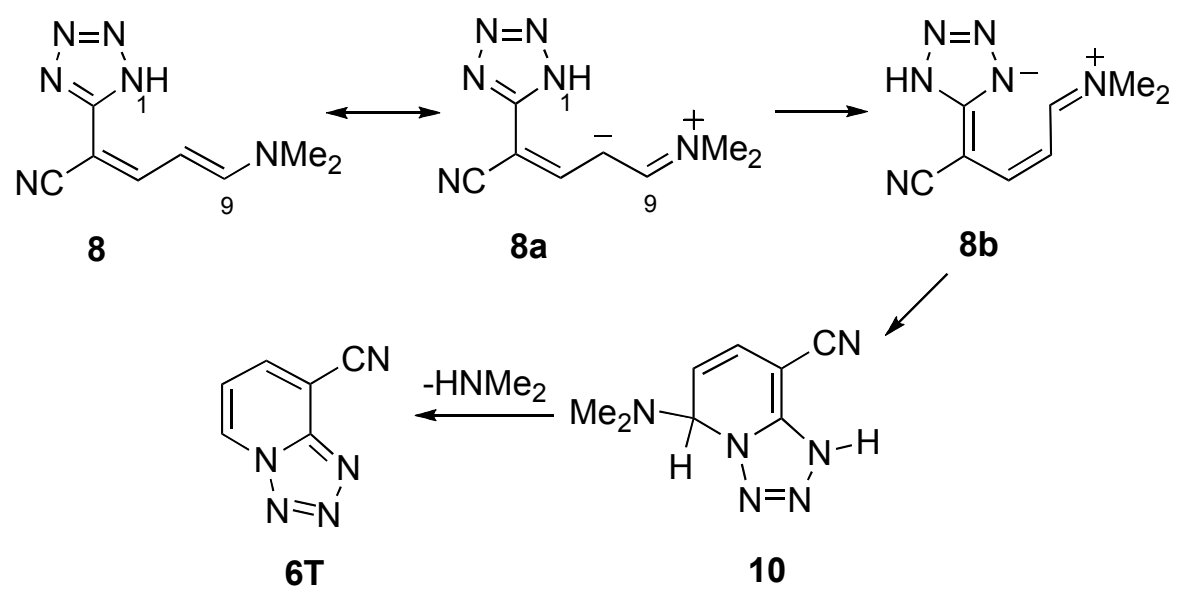

\section{Scheme 4}

Other examples of this type of nucleophilic ring opening reaction have been reported; the 2( $p$-chlorophenyl)tetrazolo[1,5-a]pyridinium tetrafluoroborate $\mathbf{1 1}$ affords the ring-opened 
dienyltetrazoles 12 with dimethylamine. ${ }^{6}$ Tetrazole $\mathbf{6 T}$ reacts with sodium hydroxide to afford a mixture of $Z, E$ - and E,E-dienyltetrazoles, 13 (Scheme 5). ${ }^{7}$

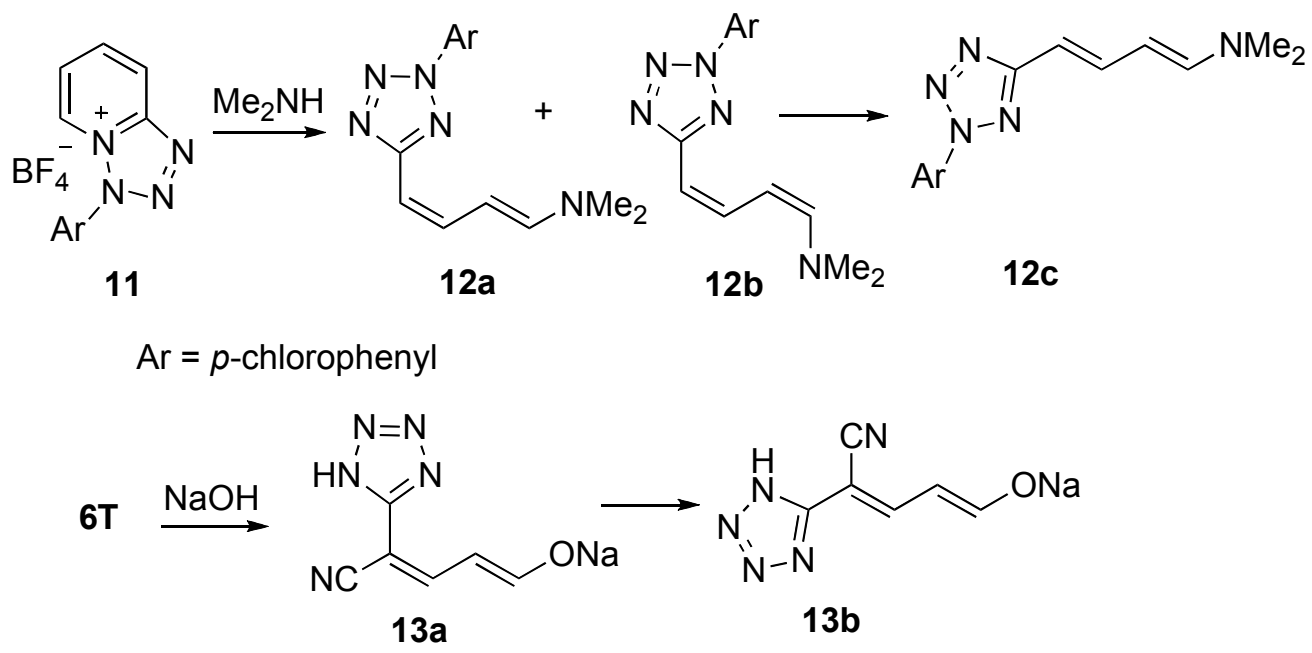

\section{Scheme 5}

The ring opening of $\mathbf{6}$ to $\mathbf{8}$ and $\mathbf{9}$ described in Scheme 3 also takes place with other secondary amines, including diisopropylamine, diethylamine and pyrrolidine. Only the reaction with diisopropylamine is slow enough to allow the diazepine 7 to be prepared successfully by rapid room temperature photolysis. It should be possible to prepare diazepines analogous to 7 (Scheme 2) from the other, more reactive amines by using low temperature photolysis.

\section{Conclusions}

Photolysis of 8-cyanotetrazolo[1,5-a]pyridine/2-azidopyridine-3-carbonitrile $\mathbf{6 T / 6 A}$ in the presence of diisopropylamine permits the isolation of the 1,3-diazepine derivative 7. However, less hindered/more nucleophilic amines attack the tetrazole 6T in position 5 in a fast, dark reaction, which results in ring opening to cyanodienyltetrazole 8 and its dimethylamine adduct 9. The reaction is reversible: heating of compound $\mathbf{8}$ causes elimination of dimethylamine and regeneration of $6 \mathbf{T}$.

\section{Experimental Section}

8-Cyanotetrazolo[1,5-a]pyridine (6T). This compound was prepared according to the literature; ${ }^{7} \mathrm{mp} 185-188{ }^{\circ} \mathrm{C}$ (dec) (lit. ${ }^{7} 183{ }^{\circ} \mathrm{C}$ ). 
4-Cyano-2-diisopropylamino-1 $\boldsymbol{H}$-1,3-diazepine (7). A solution of 6T (0.10 g, $0.69 \mathrm{mmol})$ in 90 $\mathrm{mL}$ of acetonitrile was placed in a quartz vessel and purged with $\mathrm{N}_{2}$ for $45 \mathrm{~min}$. Diisopropylamine $(1 \mathrm{~mL})$ was added, the $\mathrm{N}_{2}$ purge was discontinued, and irradiation commenced immediately at room temperature using a $1000 \mathrm{~W}$ high pressure $\mathrm{Hg}$-Xe lamp. After $2.5 \mathrm{~h}$, the orange solution was evaporated to give a brown solid, which was chromatographed on basic alumina with $25 \%$ hexane/ether. The orange band was collected and evaporated to give a yellow-orange solid, which was recrystallized by dissolving in ether and then adding hexane dropwise until precipitation commenced. Yield 0.07g (47\%). Mp 120-121 ${ }^{0} \mathrm{C}$. MS: $218\left(\mathrm{M}^{+\bullet}\right)$, 203 (-Me), 175 (-propyl radical), 161, 132. IR (KBr) cm cm $^{-1} 3375$ m, 2997 w, 2970 m, 2932 m, $2221 \mathrm{~m}, 1642 \mathrm{~m}, 1593 \mathrm{~s}, 1450$ w, 1419 w, 1366 m, 1356 m, 1332 m, 1305 w, 1230 w, 1208 m, 1137 m, 1119 m, 1042 w, 933 w, 895 w, 840 w, 764 m, 689 m. ${ }^{1}$ H NMR (DMSO-d 6,400 MHz): $\delta 1.16\left(\mathrm{~d},{ }^{3} \mathrm{~J} 6.72 \mathrm{~Hz}, 12 \mathrm{H}, 4 \mathrm{x} \mathrm{Me}\right.$ ); 3.76 (quintet, ${ }^{3} \mathrm{~J} 6.68 \mathrm{~Hz}, 2 \mathrm{H},{ }^{\mathrm{i}} \mathrm{Pr}$ ); 5.06 (dd, J $6.52 \mathrm{~Hz}, 1 \mathrm{H}$, H6); 5.70 (dd, J $6.66 \mathrm{~Hz}, 1 \mathrm{H}, \mathrm{H} 7) ; 5.78$ (d, $\left.{ }^{3} \mathrm{~J} 5.56 \mathrm{~Hz}, 1 \mathrm{H}, \mathrm{H} 5\right) ; 6.20$ (d, ${ }^{3} \mathrm{~J} 5.32 \mathrm{~Hz}, 1 \mathrm{H}, \mathrm{H} 1$; septet of ${ }^{\mathrm{i}} \mathrm{Pr}$ not fully resolved). ${ }^{13} \mathrm{C}$ NMR (DMSO-d $6,100 \mathrm{MHz}$ ): $\delta 20.9 \mathrm{Me} ; 46.9{ }^{\mathrm{i}} \mathrm{Pr} ; 113.7 \mathrm{C} 6$; 120.1 C4 or $\mathrm{CN} ; 126.0 \mathrm{C} 5 ; 127.3 \mathrm{CN}$ or C4; 136.7 C7; 157.1 C2. Anal. Calc. for $\mathrm{C}_{12} \mathrm{H}_{18} \mathrm{~N}_{4}$ : C, 66.02; H, 8.31; N, 25.67. Found: C, 66.02; H, 8.48; N, $25.63 \%$.

\section{Z,E-5-Dimethylamino-1-(1H-tetrazolyl)-1,3-butadienecarbonitrile dimethylamine adduct}

(9). Compound 6T $(0.20 \mathrm{~g}, 1.38 \mathrm{mmol})$ was dissolved in $7 \mathrm{~mL}$ of acetonitrile, and dimethylamine gas was bubbled into the solution at room temperature $\left(c a .25{ }^{\circ} \mathrm{C}\right)$ for a few seconds. The color changed immediately to yellow, and then rapidly to light orange. TLC $\left(\mathrm{Al}_{2} \mathrm{O}_{3}, \mathrm{CHCl}_{3}\right)$ revealed that 6T was no longer present. Evaporation of the solution afforded 9 $(0.31 \mathrm{~g} ; 96 \%)$. Crystallization in a refrigerator afforded yellow crystals, mp $148-150{ }^{\circ} \mathrm{C}$. Heating an acetonitrile solution of 9 to $50{ }^{\circ} \mathrm{C}$ caused partial decomposition with evolution of dimethylamine and regeneration of tetrazolopyridine 6T. Data for 9: IR $(\mathrm{KBr}) \mathrm{cm}^{-1}: 3432 \mathrm{~m}$, 3014 m, 2986 m, 2950 m, 2907 m, 2683 m, 2454 m, 2263 w, 2201 s, 2013 w, 1887 w, 1621 s, $1567 \mathrm{~s}, 1485 \mathrm{~s}, 1436 \mathrm{~m}, 1415 \mathrm{~s}, 1400 \mathrm{~s}, 1335 \mathrm{~m}, 1304 \mathrm{~m}, 1286 \mathrm{~s}, 1263 \mathrm{~m}, 1224 \mathrm{~s}, 1203 \mathrm{~s}, 1191 \mathrm{~s}$, $1134 \mathrm{~s}, 1110 \mathrm{~s}, 1066 \mathrm{~m}, 1038 \mathrm{w}, 1024 \mathrm{~m}, 1016 \mathrm{~m}, 1009$ s, $946 \mathrm{w}, 916 \mathrm{~m}, 888 \mathrm{w}, 865 \mathrm{~m}, 824 \mathrm{~m}$, 768 w, 742 w, 727 w, 691 m, 607 w, 577 w, 504 w, 476 w, 439 w. ${ }^{1}$ H NMR (DMSO-d 6 , 400 $\mathrm{MHz}): \delta 2.60\left(\mathrm{~s}, 6 \mathrm{H},\left(\mathrm{CH}_{3}\right)_{2} \mathrm{NH}\right) ; 2.95\left(\mathrm{br} \mathrm{s}, 6 \mathrm{H},\left(\mathrm{CH}_{3}\right)_{2} \mathrm{~N}-\mathrm{R}\right) ; 6.50\left(\mathrm{t},{ }^{3} \mathrm{~J} 12.28 \mathrm{~Hz}, 1 \mathrm{H}, \mathrm{H} 8\right) ; 6.97$ (d, ${ }^{3} \mathrm{~J} 11.92 \mathrm{~Hz}, 1 \mathrm{H}, \mathrm{H} 7$ or H9); 7.12 (d, ${ }^{3} \mathrm{~J} 12.60 \mathrm{~Hz}, 1 \mathrm{H}, \mathrm{H} 9$ or $\left.\mathrm{H} 7\right)\left(\mathrm{NH}\right.$ not observed). ${ }^{13} \mathrm{C}$ NMR (DMSO-d $6,100 \mathrm{MHz}): \delta 34.9\left(\mathrm{CH}_{3}\right)_{2} \mathrm{NH} ; 84.5 \mathrm{C} 6 ; 97.3 \mathrm{C} 8 ; 123.7 \mathrm{CN} ; 147.0 \mathrm{C} 7 ; 154.1$ C9; 158.3 C5. Anal. Calcd for $\mathrm{C}_{10} \mathrm{H}_{17} \mathrm{~N}_{7}$ (9): C, 51.05; H, 7.28; N, 41.67. Found: C, 50.86; H, $7.33 ; \mathrm{N}, 41.94 \%$.

\section{Removal of dimethylamine from 9 to give 8 .}

Compound $9(0.05 \mathrm{~g}, 0.21 \mathrm{mmol})$ was dissolved in water $(0.5 \mathrm{~mL})$, and 2 drops of $32 \% \mathrm{HCl}$ were added. A yellow precipitate of $\mathbf{8}$ formed. Water $(2 \mathrm{~mL})$ was added, and the mixture was transferred to a Buchner funnel, where it was washed with water then dried under suction. Recrystallization was achieved with acetonitrile or methanol. Yield 0.035 g (87\%). Mp 128- 
$129{ }^{0} \mathrm{C}(\mathrm{dec})$. IR (KBr) cm ${ }^{-1}: 3549 \mathrm{w}, 3423 \mathrm{w}, 3125 \mathrm{w}, 3027 \mathrm{w}, 2917 \mathrm{w}, 2773 \mathrm{w}, 2638 \mathrm{w}, 2498$ w, $2206 \mathrm{~m}, 1636 \mathrm{~s}, 1581 \mathrm{~s}, 1477 \mathrm{~m}, 1420 \mathrm{~s}, 1410 \mathrm{~s}, 1340 \mathrm{w}, 1311 \mathrm{w}, 1280 \mathrm{~m}, 1240 \mathrm{~m}, 1202 \mathrm{w}$, 1119 m, 1090 m, 1014 w, 980 m, 917 w, 866 w, 812 w, 756 w, 740 w, 701 w, 597 w, 432 w. ${ }^{1} \mathrm{H}$ NMR (DMSO-d 6 , 400 MHz): $\delta 2.97$ (s, 3H, Me); 3.18 (s, 3H, Me); $5.46\left(\mathrm{t},{ }^{3} \mathrm{~J} 12.16 \mathrm{~Hz}, 1 \mathrm{H}, \mathrm{H} 8\right.$ ); 7.56 (d, ${ }^{3} \mathrm{~J} 11.96 \mathrm{~Hz}, 1 \mathrm{H}, \mathrm{H} 7$ or H9); 7.81 (d, ${ }^{3} \mathrm{~J} 12.32 \mathrm{~Hz}, 1 \mathrm{H}, \mathrm{H} 9$ or H7) (NH not observed); ${ }^{13} \mathrm{C}$ NMR (DMSO-d 6 , 100 MHz): $\delta 37.2 \mathrm{Me} ; 44.8 \mathrm{Me} ; 74.7$ C6; 95.5 C8; 117.7 CN; 152.2 C7; 153.9 C5; 157.5 C9. Anal. Calc. for $\mathrm{C}_{8} \mathrm{H}_{10} \mathrm{~N}_{6}$ : C, 50.52; H, 5.30; N, 44.18. Found: C, 50.58; H, 5.39; $\mathrm{N}, 43.98 \%$.

\section{Crystallography}

Cell constants were determined by least-squares fits to the setting parameters of 25 independent reflections measured on an Oxford Diffraction Gemini CCD diffractometer employing graphitemonochromated Mo K $\alpha$ radiation $(0.71073 \AA)$. Data reduction and absorption correction was performed with the CrysAllis package. ${ }^{8}$ The structure was solved by direct methods with SHELXS and refined by full-matrix least-squares analysis with SHELXL-97. ${ }^{9}$ All non-H atoms were refined with anisotropic thermal parameters. H-atoms were included in estimated positions using a riding model. Drawings were produced with ORTEP. ${ }^{10}$

Crystal data. Compound $8 \cdot 1 / 2 \mathbf{M e O H}: \mathrm{C}_{8.5} \mathrm{H}_{12} \mathrm{~N}_{6} \mathrm{O}_{0.5}, \mathrm{M}=206.24$, triclinic, space group $\mathrm{P} \quad \overline{1}$, a $=8.0828(4), \mathrm{b}=15.6043(8), \mathrm{c}=17.3420(9) A, \alpha=87.289(4), \beta=77.839(4), \gamma=87.795(4)^{\circ}$, $\mathrm{U}=2134.9(2) A^{3}, \mathrm{Z}=8, \mathrm{D}_{c}=1.283 \mathrm{~g} \mathrm{~cm}^{-3}, \mu=0.090 \mathrm{~mm}^{-1}, 16168$ reflections measured, 7365 unique $\left(\mathrm{R}_{\text {int }}=0.0475\right.$ ), $\mathrm{R}_{1}=0.0581$ (for 2794 observed data, $\mathrm{I}>2 \sigma$ ), $\mathrm{wR}_{2}=0.1118$ (all data).

\section{Acknowledgements}

This research was supported by the Australian Research Council and by an Australian Postgraduate Scholarship to C. A. We thank Dr David Kvaskoff for help with the crystallization of 8 .

\section{Supplementary information}

Crystallographic data for compound $\mathbf{8} \cdot 1 / 2 \mathbf{M e O H}$ have been deposited with the Cambridge crystallographic Data Centre (CCDC 698469). This information can be obtained free of charge from The Director, CCDC, 12 Union Road, Cambridge, CB2 1EZ, UK (fax: +44-1223-336033; e-mail: deposit@ccdc.cam.ac.uk or http://www.ccdc.cam.ac.uk). 


\section{References}

1. Part 1: Reisinger, A.; Wentrup, C. ARKIVOC 2005, (xiv), 131.

2. van der Plas, H. C. Ring Transformations of Heterocycles, Vol. 1 and 2, Academic Press: London, New York, 1973.

3. Reisinger, A.; Bernhardt, P. V.; Wentrup, C. Org. Biomol. Chem. 2004, 2, 246.

4. Reisinger, A.; Koch, R.; Bernhardt, P. V.; Wentrup, C. Org. Biomol. Chem. 2004, 2, 1227.

5. Addicott, C.; Wentrup, C. Aust. J. Chem. 2008, 61, 592.

6. Gelleri, A.; Messmer, A.; Nagy, S.; Radics, L. Tetrahedron Lett. 1980, 21, 663. See also Messmer, A.; Hajos, G.; Timari, G. Tetrahedron 1992, 48, 8451.

7. Pollak, A.; Polanc, S.; Stanovnik, B.; Tisler, M. Monatsh. Chem. 1972, 103, 1591.

8. Farrugia, L. J. J. Appl. Crystallogr., 1999, 32, 837.

9. G. M. Sheldrick, SHELX97 - Programs for Crystal Structure Analysis (Release 97-2), Institut für Anorganische Chemie der Universität, Tamstrasse 4, D-3400, Göttingen, Germany, 1998.

10. Farrugia, L. J. J. Appl. Crystallogr., 1997, 30, 565. 